\section{Spatial dynamics of AIDS incidence in the elderly in Rio de Janeiro, Brazil, 1997-2011}

\author{
Dinâmica espacial da incidência da AIDS em idosos \\ no Rio de Janeiro, Brasil, 1997-2011
}

\author{
Dinámicas espaciales de la incidencia del SIDA \\ en adultos de edad avanzada en Río de Janeiro, \\ Brasil, 1997-2011
}

\author{
Nádia Cristina Pinheiro Rodrigues 1,2 \\ Andrea Sobral de Almeida 1 \\ José Ueleres Braga 1,3 \\ Gisele O'Dwyer ${ }^{1}$ \\ Paulo Cavalcante Apratto Junior 2 \\ Regina Paiva Daumas 1 \\ Valéria Teresa Saraiva Lino 1 \\ Mônica Kramer de Noronha Andrade 1 \\ Denise Leite Maia Monteiro 2 \\ Mônica Bastos de Lima Barros 1
}

\title{
Resumo
}

\footnotetext{
${ }^{1}$ Escola Nacional de Saúde Pública Sérgio Arouca, Fundação Oswaldo Cruz, Rio de Janeiro, Brasil. 2 Faculdade de Ciências Médicas, Universidade do Estado do Rio de Janeiro, Rio de Janeiro, Brasil.

3 Instituto de Medicina Social, Universidade do Estado do Rio de Janeiro, Rio de Janeiro, Brasil.

Correspondence N. C. P. Rodrigues Escola Nacional de Saúde Pública Sergio Arouca Fundação Oswaldo Cruz. Rua Leopoldo Bulhões 1480 Rio de Janeiro, $R J$ 21041-210, Brasil. nadiacristinapr@gmail.com
}

\begin{abstract}
The dynamics of the spread of the AIDS epidemic ranges according to the characteristics of each geographical region in different popula tion groups. The aim of this study was to evaluate spatial and temporal trends of the AIDS epidemic among the elderly in the State of Rio de Janeiro, Brazil. A retrospective study using spatial analysis techniques was conducted among AIDS cases ( $\geq 60$ years) diagnosed from 1997-2011. The Poisson regression model was used to assess the relationship between year of diagnosis and incidence of AIDS, adjusted by sex. The AIDS epidemic began in the south coast of the state and gradually reached neighboring cities. The highest rates were found in regions around Rio de Janeiro and Niterói cities. The highest smoothed rates of the period were observed in Niteroi in 2002-2006: 11.87/100,000 (men) and 8,5/100,000 (women). AIDS incidence rates among the elderly have stabilized in recent decades. To prevent HIV from spreading further among the general population, greater attention should be given to the older population.
\end{abstract}

Acquired Immunodeficiency Syndrome; HIV; Aged; Spatial Analysis
A dinâmica de espalhamento da epidemia de AIDS varia segundo as características de cada região geográfica nos diferentes grupos populacionais. O objetivo deste trabalho foi avaliar tendências temporais e espaciais da epidemia de AIDS em idosos no Estado do Rio de Janeiro, Brasil. Estudo retrospectivo com técnicas de análise espacial, utilizando-se casos de AIDS $(\geq 60$ anos) diagnosticados de 1997-2011. O modelo de regressão de Poisson foi utilizado para acessar a relação entre ano diagnóstico e incidência de AIDS ajustada por sexo. A epidemia de AIDS começou no litoral sul do estado e, gradualmente, chegou às cidades vizinhas. As maiores taxas da doença foram encontradas em regiões em torno do Rio de Janeiro e Niterói. Em 2002-2006, na cidade de Niterói, foram observadas as maiores taxas suavizadas no período: 11,87/100 mil (homens) e 5,08/100 mil (mulheres). Os índices de AIDS em idosos têm estabilizado nas últimas décadas. Maior atenção deve ser dada ao grupo idoso para evitar a progressão da doença na população.

Síndrome de Imunodeficiência Adquirida; HIV; Idoso; Análise Espacial 


\section{Introduction}

The profile of the AIDS epidemic has been changing over time. AIDS, initially associated with gay men, began to reach people of different ages, genders and sexual orientations, spreading in different areas, according to the peculiarities of each region. The limited investment in prevention programs targeting elderly populations may have contributed to the increase in AIDS incidence rates in this group $1,2,3,4$.

The elderly represent a population particularly vulnerable to sexually transmitted infection (STI). Although not recognized as a risk group for STI, sexually active older people can be particularly vulnerable to these diseases because of behavioral aspects such as condom usage. Driemeier et al. 5, analyzing elderly vulnerability to STI in 2009 , found that only $14 \%$ of respondents reported use of condoms.

Global data shows an increasing number of AIDS cases in older people 6,7. Lazarus et al. found that in $2007,12.9 \%$ and $3.7 \%$ of newly reported HIV cases in Western and Eastern Europe, respectively, occurred in people aged 50 years or more. In Central Europe, around one in 10 newly reported HIV cases occurred in people aged 50 years or more ${ }^{8}$. In the United States, the AIDS incidence rate in the population aged 65 or above is approximately 1.60 per $100,0009,10$.

In Brazil, studies have also noted that AIDS rates are increasing in the elderly. The findings of a Brazilian study (1980-2008) indicated that AIDS incidence among people aged 50 or older accounted for $10 \%$ of new AIDS cases in the country, and the annual incidence in the period was 7.8/100,000. Although Brazilian reported AIDS cases have remained stable in adults and even decreased in children and adolescents, a steady increase was observed among people aged 50 and over from 2001 to 200811.

\section{Spatial distribution of AIDS}

Studies involving geoprocessing techniques have been performed to assess the spatial dynamics of AIDS in different populations. Jongsthapongpanth \& Bagchi-Sen 12 evaluated AIDS mortality data (2000-2004) and detected significant geographical variations in HIV/AIDS death rates at the sub-district level in Thailand. Studies performed in the United States (1996) found that AIDS is more frequent in males, in the northeast part of the country and in large metropolitan areas 13,14 . Several studies have shown that a person's need for HIV/AIDS treatment and care can affect where they choose to live $15,16,17$.
A Brazilian study found that the process of diffusion of AIDS across states over time (19871996) seems to have initiated in large metropolises or in cities with large populations 18 . Towns with larger populations had a reduction or exhibited a stabilizing trend, while smaller cities showed a lower magnitude of the epidemic 19,20. Szwarcwald et al. 21 analyzed the epidemic of AIDS in adults in the city of Rio de Janeiro from 1988 to 1996 and found high rates in the center of the city and in coast areas initially. Over time, the authors observed a visible expansion of the epidemic from the coast to the interior.

The interiorization of AIDS appears to involve several key aspects, including the spreading trend of the epidemic from the largest urban centers to others areas. Methodological problems occur when rates of small municipalities are analyzed, due to the instability of the indicators generated by small numbers of people and events (cases and deaths). To circumvent this problem, strategies for smoothing the original values are usually adopted. In a southeastern Brazilian state, an irregular interiorization pattern of the AIDS epidemic was observed over several years. High rates of the disease were detected in towns near others with low incidence rates, most likely due to random fluctuations resulting from small population sizes. The authors calculated smoothing rates using a Bayesian model to reduce random fluctuations 22 .

The aim of this study was to analyze the spatial dynamics of the AIDS epidemic in the elderly (individuals aged 60 years or more) in the state of Rio de Janeiro from 1997 to 2011.

\section{Materials and methods}

An ecological study was conducted in the state of Rio de Janeiro using spatial analysis as a technique for data processing. Methods for analyzing spatial data address events aggregated by geographic unit. Therefore, a general area is used because the exact location of the events is unknown. In this study, the municipality was used as the geographical unit for analysis.

The State of Rio de Janeiro is located in southeastern Brazil and its capital is Rio de Janeiro city located on the southern coast of the state.

\section{Study population}

All subjects included in this study were diagnosed with AIDS between 1997-2011. Population data by sex and year of diagnostic were obtained from population censuses (1991, 2000 and 2010), population count (1996) and inter-census pro- 
jections. Information on the number of reported AIDS cases by municipality, sex, year of diagnosis, recorded in the period 1997-2011, were obtained from DATASUS (Brazilian Health Informatics Department), which is a national database that aggregates AIDS cases from the Brazilian Information System for Notifiable Diseases (SINAN), Mortality Information System (SIM) and Control System Laboratory Tests (SISCEL). SINAN data are collected from the AIDS notification forms completed in the health units ${ }^{23}$. SIM registry is done through death certificates 24 . SISCEL data come from a network of laboratories that cater to public health.

AIDS cases were defined according to the technical standard of the Ministry of Health definition of AIDS cases in adults for the purposes of epidemiological surveillance 25 .

\section{Statistical methods}

In this paper we apply spatial analysis techniques, more specifically the preparation of thematic maps; the use of indicators of global and local spatial dependence; ending with Poisson modeling.

We used the georeferenced mesh of municipalities of the state of Rio de Janeiro (shapefile file), available from the Brazilian Institute of Geography and Statistics (IBGE. http://www.ibge. gov.br/mapa_site/mapa_site.php\#geociencias, accessed on 20/Aug/2014), allowing the preparation of thematic maps.

Incidence rates per 100,000 individuals were calculated for the geographic units by counting the number of new AIDS cases in individuals aged 60 years or more and the municipality's population size in the same age group.

To reduce the instability of indicators caused by the number of cases and small population size, indicators were aggregated into 5-year periods (1997-2001, 2002-2006 and 2007-2011), and the Local Empirical Bayesian method smoothing strategy was used to transform the original data 26 . The most recent periods - 2012 and 2013 - were not included in the analysis due to delay problems in the notification system.

To verify the presence of spatial dependence, we used a global statistical test, in which the null hypothesis was that there is a random distribution of incidence rates in the municipalities of the state of Rio de Janeiro, and the alternative hypothesis was the existence of a significant association of similar or different values. These global statistics summarize in a single indicator, the overall scheme of spatial dependence Moran's I 26,27.
The Global Moran index can be defined by the formula below 27 :

$I=\frac{\left[\left(n \Sigma_{i}^{n} \Sigma_{j}^{n} \omega_{i j}\left(y_{i}-\bar{y}\right)\left(y_{j}-\bar{y}\right)\right]\right.}{\left[\Sigma_{i}^{n}\left(y_{i}-\bar{y}\right)^{2} \Sigma_{i}^{n} \Sigma_{j}^{n} \omega_{i j}\right]}$

where, $\omega_{i j}$ is an element of contiguity matrix $\omega$; $y_{i}$ is the incidence rate of municipality $i ; y_{j}$ is the incidence rate of municipality $j ; \bar{y}$ is the sample mean and $n$ is the total number of cities.

Complementing the Global Moran I, LISA statistics were used, which are the Local Indicators of Spatial Association. LISA Maps were constructed to show potentially distinct spatial correlation regimes in different sub-regions.

The Local Moran index can be defined by the formula below 27:

$I=\frac{n\left[\left(Z_{i} \Sigma_{j}^{n} \omega_{i j} Z_{j}\right)\right.}{\left(\Sigma_{j}^{n} Z_{j}^{2}\right)}$

where, $z_{i}=y_{i}-\bar{y} ; z_{i}=y_{i}-\bar{y} ; \omega_{i j}$ is an element of contiguity matrix $\omega ; y_{i}$ is the incidence rate of municipality $i$; $y_{i}$ is the incidence rate of municipality $j ; \bar{y}$ is the sample mean and $n$ is the total number of cities.

To perform this work, we formulated a binary spatial weight matrix $(\omega)$, whereby two counties are neighbors if they share a common physical boundary. When this occurs, the value 1 (one) is assigned in the matrix, otherwise, the value 0 (zero) was assigned. In the studies of STI diseases, like AIDS, neighboring cities have a stronger interaction with each other than those that don't have common border. In these situations, the matrices defined by the principle of contiguity type Queen or Rook are used. The Queen matrix considers two neighboring regions sharing a common border, analyzing also the vertices. The Rook matrix, by definition, is simpler, as it considers only neighboring regions which have a common border 28 .

Poisson regression analysis was used to assess the risk of AIDS occurrence by sex and year of diagnostic. Poisson regression is the most common strategy for modeling count data; however, when models present overdispersion, this technique does not produce reliable estimates 29 . As the Poisson model did not show significant dispersion, it was used in the analysis. The factors included in this model were sex and year of diagnostic. A logarithmic link function (i.e., logarithm of the population), used as an offset, was added to the model.

Model specification:

\section{$Y \sim$ Poisson $(\mu)$}

$\log \left(\mu_{\text {cases }}\right)=\alpha+\beta_{1} \times \operatorname{sex}+\beta_{2} \times$ year of diagnostic + $\log$ (population) 
Where $\mu$ is the average number of expected cases, $\alpha$ is the model intercept and $\beta$ corresponds to regression coefficients. The year of diagnostic was included as a dummy variable; the following was used as reference groups: 1997 (i.e., the earliest year of diagnostic).

Graphical model and maps were used to present the analyzed results. All analyses were performed with TerraView (version 4.2.2. Instituto Nacional de Pesquisas Espaciais; http:// www.dpi.inpe.br/terraview) and R-Project (version 3.1.1. The R Foundation for Statistical Computing, Viena, Austria; http://www.r-project.org) software.

\section{Results}

An increasing trend of AIDS incidence in Rio de Janeiro State in the time periods (1997-2001, 2002-2006, 2007-2011) was detected in both genders. We observed a $17.71 \%$ increase in the rate in men and a $50.54 \%$ increase in the rate in women from the first to the last period analyzed (Table 1). The average rate (interval: 3 ) in older males fluctuated throughout the study period, with minimum of 6.15/100,000 in 2001 and maximum of 8.34/100,000 in 2004. In older women, an increased rate was observed until 2006 (peak year), reaching a maximum of 3.77/100,000.

Figure 1 shows the spatial distribution of AIDS incidence rates in the elderly by gender for the towns of Rio de Janeiro State from 1997 to 2011 in five-year periods. In men, it appears that during 1997-2001 only four of the 92 towns showed greater than 20 cases per 100,000 individuals; $25 \%$ had rates up to 20 cases per 100,000 , while the remainder $(70 \%)$ presented zero cases during that time period. A spreading trend can be difficult to identify due to the presence of cities with large population sizes interspersed with other cities with small population size. However, on the southern coast of the state, where great metropolitan areas (Rio de Janeiro and Niterói) are located, one may notice a group of cities with rates up to 20 cases per 100,000. This concentration becomes more pronounced in subsequent time periods, when a gradual spreading of the epidemic from the south coast to the north of Rio de Janeiro State seems to occur. In women during 1997-2001, only two counties had rates higher than 20 cases per $100,000,19 \%$ had a maximum of 10 cases per 100,000 , while the remainder (79\%) did not present any case in the period. Like the pattern observed in males in the first period, there seemed to be a concentration of counties with higher rates (up to 10 cases per 100,000) located on the southern coast of the state. In subsequent periods, one can observe several towns with high rates of AIDS among the elderly in the northeastern of the state.

We could not detect a significant global correlation using the global Moran index. Figure 2 shows the distribution of smoothed rates of AIDS using the Local Empirical Bayesian method. The highest rates of AIDS in men are located in the two major urban centers of the south coast of the state, Rio de Janeiro and Niterói. Over time there is a gradual increase in disease rates in neighboring cities. Moreover, although the highest raw rate in males (Figure 1) was 106/100,000 in the small town of Carapebus during 2007-2011, after smoothing of the original values (Figure 2), the highest rate was determined to be much lower: 11.87/100,000 in Niterói during 2002-2006. After smoothing, several cities previously classified as high or low incidence changed categories and the data began to better reflect the actual risk of AIDS

\begin{tabular}{lccc}
\hline Year of diagnosis/Sex & Average number of cases & Population mean & Weighted average rate/100,000 \\
\hline $\begin{array}{l}\text { 1997-2001 } \\
\text { Male }\end{array}$ & 0.43 & & 3.38 \\
Female & 0.23 & $6,574.40$ & 1.53 \\
$2002-2006$ & 0.57 & $7,124.57$ & 3.80 \\
Male & 0.37 & $10,237.80$ & 2.90 \\
Female & & & 4.21 \\
$2007-2011$ & 0.63 & $8,999.85$ & 3.09 \\
Male & 0.40 & $12,792.60$ & \\
Female & & & \\
\hline
\end{tabular}



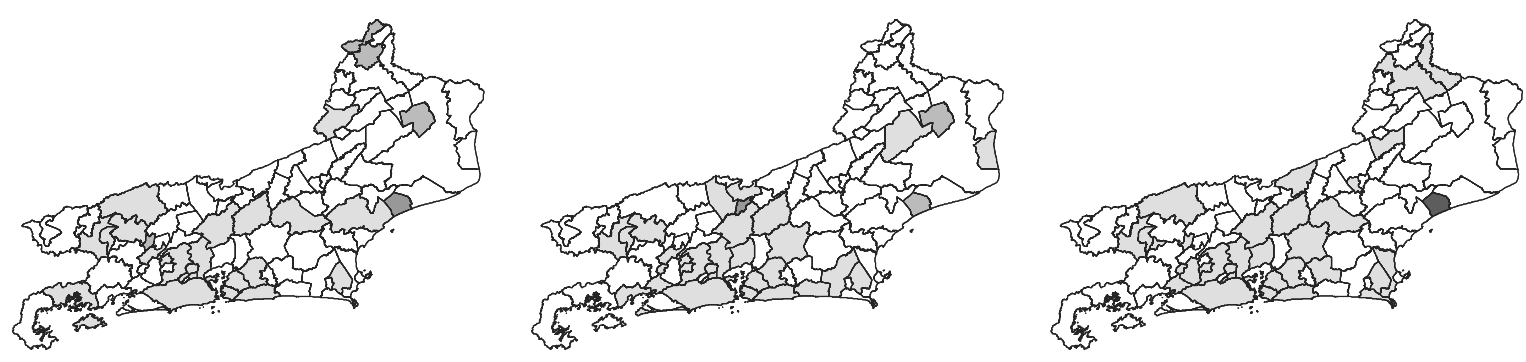

Rate/100,000

1b) Female (1997-2001)
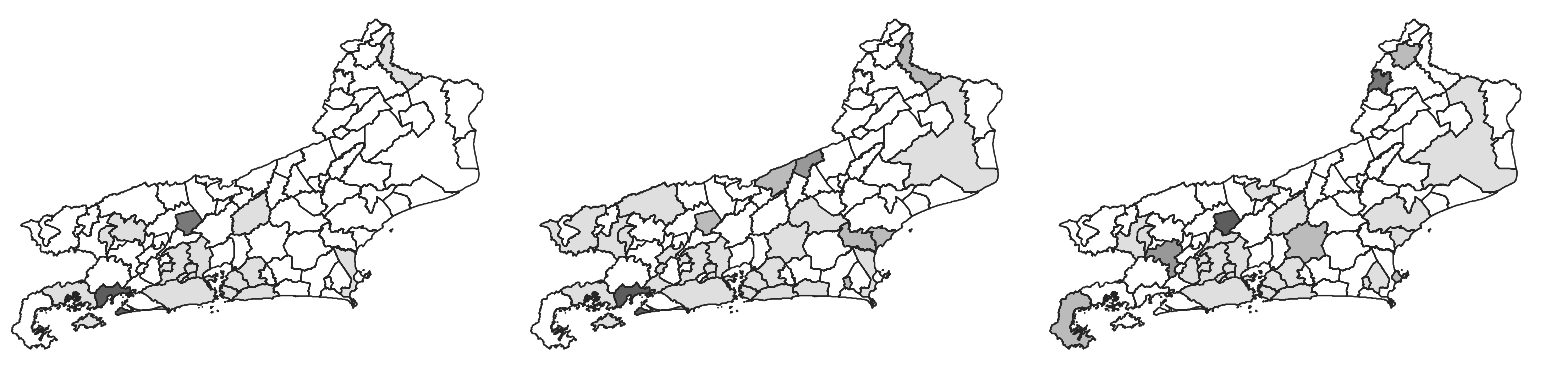

Rate/100,000

0.00

$0.01-10.00$

$10.01-20.00$

$20.01-30.00$

$30.01-39.99$

$\geq 40.00$

$\geq 80.00$

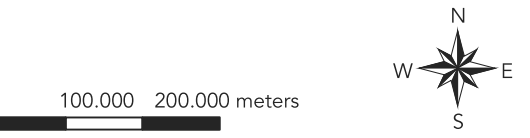

in the elderly instead of reflecting random fluctuations. Like men, the highest raw rates of AIDS in women were observed in the large urban centers of the south coast (Rio de Janeiro and Niterói). During 2002-2006, high rates were also observed in the northeast and north of Rio de Janeiro. Over time, a gradual increase of the epidemic in areas neighboring the large centers (on the southern coast) can also be observed in women. While the highest raw rate among women was 48/100,000 in the small town of Paty do Alferes during 20072011 (Figure 1), after smoothing of the original values, the highest rate became 5.08/100,000 in Niterói during 2002-2006 (Figure 2).

Figure 3 represents the LISA map, which compares the normalized AIDS rate in a given area with the average rates of its neighbors. For both sexes, high rates in cities neighboring major urban centers of the south of the state were observed. As these cities are surrounded by cities with high rates, they are classified as "high-high" (Q1 - dark coloring). Over the years, other neighbors started to present with high rates, following the same trend of the overall neighborhood. This pattern was also found in northeastern Rio de Janeiro during 2002-2006 for women. Dark gray color was predominant in all of the LISA maps, except for women in the first period when none of the rates were statistically significant. This predominant pattern, represented by the dark gray coloring, indicates that most of the cities had a low incidence of AIDS, following the same trend as their neighbors (Q2: low-low). In both sexes, the vast majority of "low-low" cities were statistically significant. In the last period, there was an increase in the number of type Q1 (high-high) cities neighboring Rio de Janeiro whose indexes were statistically significant (Figure 3). 


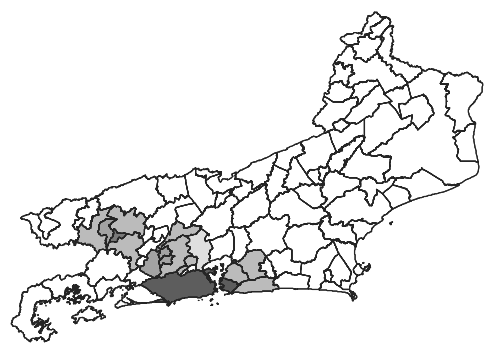

2b) Female (1997-2001)

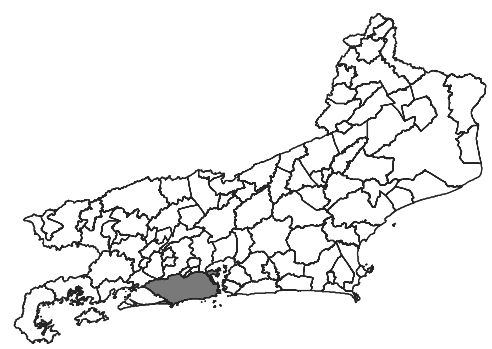

2c) Male (2002-2006)

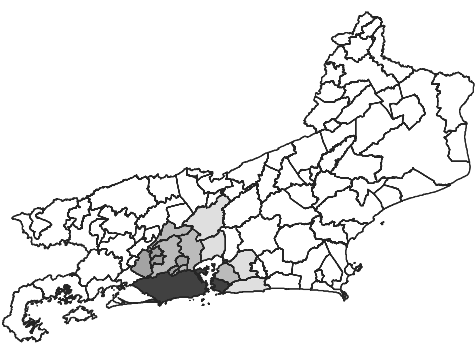

2d) Female (2002-2006)

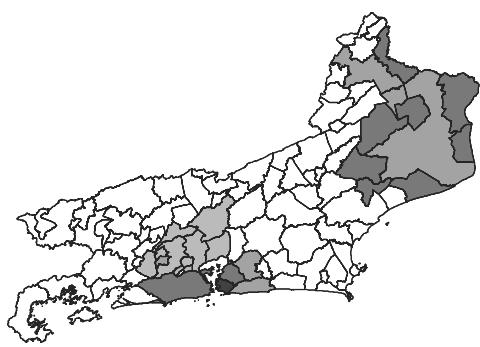

2e) Male (2007-2011)

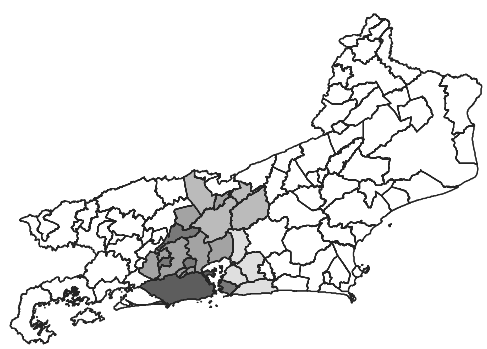

Rate/100,000

0.00

$0.01-2.00$

$2.01-4.00$

4.01-6.00

$6.01-8.00$

8.01-9.9

$\geq 10.00$

2f) Female (2007-2011)

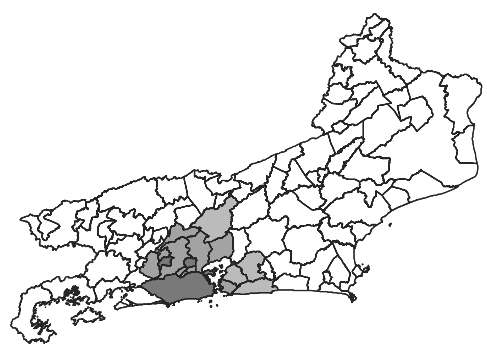

Rate/100,000

0.00

$0.01-1.00$

$1.01-2.00$

2.01-3.00

$3.01-4.00$

4.01-4.99

$\geq 5.00$
In men, we detected a direct association between the rates in the county and the region for $66-75 \%$ of the counties - only $15-24 \%$ of these had high rates of the disease in regions of high incidence; the others showed lower rates in regions of low incidence. In women, $51-64 \%$ of the counties showed a direct association between the rates in the county and the region and only $18-19 \%$ of these showed high rates of the disease in areas of high incidence; the others showed lower rates in low-incidence region (Figure 3).

The general pattern of the rates represented in the LISA map indicates that the spatial distribution pattern of the disease in older women became more similar to that in men from 20072011. In this period, we can observe clusters with high rates of disease nearby Rio de Janeiro. In contrast, we could identify in women two clusters presenting high rates of disease during 2002-
2006. The first cluster is located in the neighborhood of the largest cities of the south of the state, and the second covers a large area north east of Rio de Janeiro State. This latter cluster was not observed in men (Figure 3).

In the first study period, the small city of Paracambi was found to be an area at risk for an increased epidemic in men because, despite having lower rates of the disease, the average rates of the surrounding neighborhood were high (Q4: low-high). However, in the subsequent period the rates of the disease decreased in Paracambi and in its northern neighbors (Figure 3). Like the male pattern observed in the first period, a similar pattern was observed in women in the last study period. Paracambi city showed again a "low-high" pattern. In addition, in 2002-2006 Carapebus (northeastern part of the state) was also found to be a risk area for 


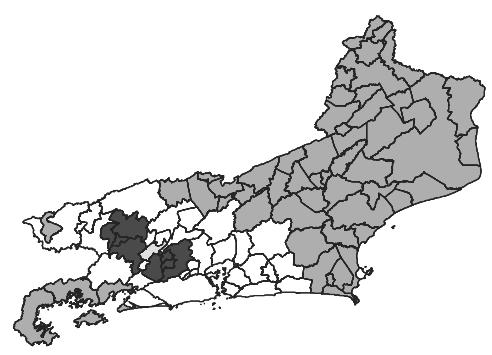

3b) Female (1997-2001)

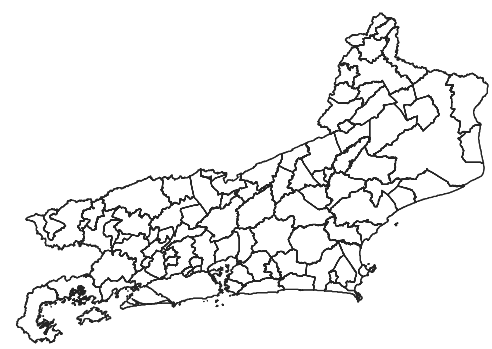

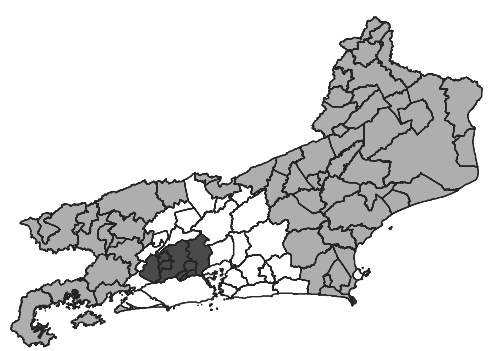

3d) Female (2002-2006)

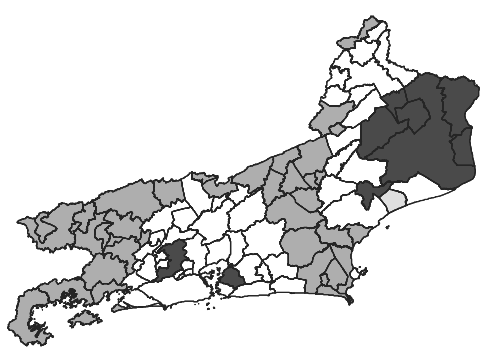

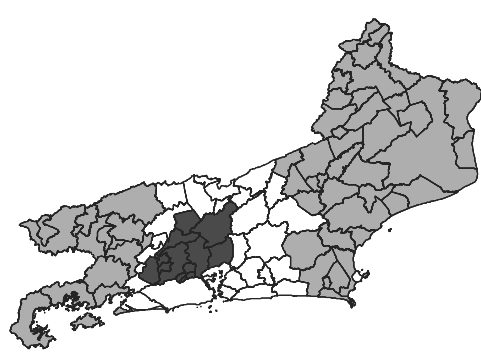

LISA map

Not significanty

Hight-hight (Q1)

Low-low (Q2)

Hight-low (Q3)

Low-hight (Q4)

3f) Female (2007-2011)

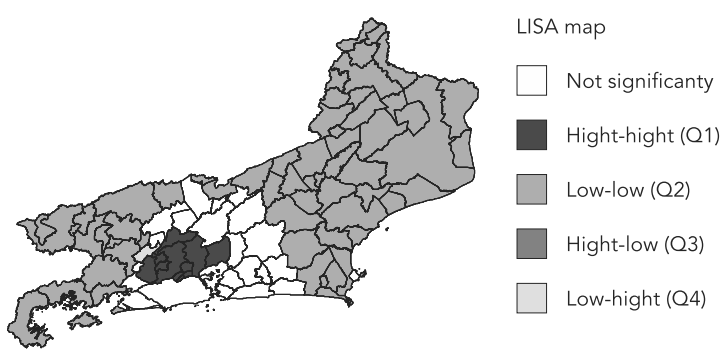

$0 \quad 100.000 \quad 200.000$ meters

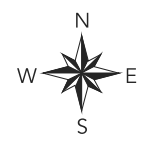

* Empirical bayesian local rates in elderly

the epidemic in women, presenting a pattern of type "low-high".

Sex was an important factor to explain the occurrence of AIDS in the elderly (Table 2). The risk of AIDS occurrence adjusted by year of diagnostic was 2.26 times greater in men than in women. Table 2 shows the relationship with the period (diagnostic year) and the incidence rate of AIDS in the elderly, adjusted by sex. There was an increase of AIDS rates in each period as compared to 1997-1999. We could observe a high pick in the AIDS rate ratio in 2003-2005. After that, the rate ratio remains constant over time (Table 2).

\section{Discussion}

In the present study, we chose to analyze the incidence of AIDS from 1997 to 2011 by focusing on the period after the introduction of cART (combination Antiretroviral Therapy), which impacted on changes such as substantial improvements in survival.

Rio de Janeiro is a State of great socioeconomic diversity; aggregate data may mask regional and local inequalities. In the greatest cities, like Niterói and Rio de Janeiro, it is common to detect inequalities inside the same city. Close to where people of high socioeconomic conditions live, there are also slum dwellers who live in poor conditions.

Brazilian studies have shown that men have shown 2-3 times greater risk of AIDS occurrence 
Sex and period effects on AIDS incidence * (age $\geq 60$ years), 1997-2011.

\begin{tabular}{|c|c|c|c|c|c|}
\hline Main factors/Categories & Coefficent & RR & \multicolumn{2}{|c|}{$95 \% \mathrm{Cl}$} & p-value \\
\hline \multicolumn{6}{|l|}{ Sex (reference: female) } \\
\hline Male & 0.82 & 2.26 & 2.02 & 2.54 & $<0.001$ \\
\hline \multicolumn{6}{|c|}{ Year of diagnosis (reference: 1997-1999) } \\
\hline $2000-2002$ & 0.16 & 1.17 & 0.96 & 1.44 & $<0.14$ \\
\hline $2003-2005$ & 0.34 & 1.41 & 1.16 & 1.71 & $<0.001$ \\
\hline $2006-2008$ & 0.22 & 1.25 & 1.03 & 1.52 & $<0.03$ \\
\hline 2009-2011 & 0.22 & 1.25 & 1.04 & 1.52 & $<0.03$ \\
\hline
\end{tabular}

95\% $\mathrm{Cl}$ : 95\% confidence interval; RR: rate ratio.

* The poisson model was used to estimate the rate ratio of AIDS incidence in the elderly in Rio de Janeiro State. Factors included in the model "sex and period".

than women 30,31 and the peak of AIDS incidence was around 2002 in Rio de Janeiro State 31 . Apratto Junior et al. 30, detected in elderly people of Niterói a peak of AIDS incidence around 2004.

According to the findings of national and international studies, there seems to be a county-level association between HIV/AIDS diagnosis rates and socioeconomic disadvantage 32,33 Many workers in large urban centers, usually with low socioeconomic status, choose to live in nearby towns. Because of this, it would be expected that neighboring areas of large cities were following the disease pattern trend of these large urban centers.

Brazilian metropolises and regional urban centers seem to play an important role in the spreading of the epidemic, not only because of their population density but also because they are centers of trade and social interaction 34,35 . Furthermore, the best hospitals with modern equipment for diagnosis and treatment are located in the largest cities.

Grangeiro et al. ${ }^{20}$, studying Brazilian cases of AIDS during 2002-2006, observed that the epidemic remains concentrated in urban centers, and the spread of cases to the countryside is characterized by an irregular occurrence with a small magnitude. Reis et al. 22 employed indicator smoothing using the empirical Bayesian estimator to analyze a state in the southeast of Brazil during 1988-2002. The authors found significant differences between mean crude incidence rates and rates recalculated by the empirical Bayesian estimator. The maps showed interiorization of the epidemic across periods and less fragmented identification of municipalities with the highest concentrations of cases.

Studies carried out in the USA detected a greater proportion of AIDS cases in large met- ropolitan areas. Fewer AIDS cases are reported from smaller communities 14,36.

The number of cases in small towns may have led to methodological problems. Our findings showed that in the first, second and third study periods, 54,49 and $37 \%$ of the cities, respectively, had fewer than 3,000 elderly inhabitants. Reis et al. 22 reported a similar problem, investigating the cities of another state in southeastern Brazil from 1988 to 2002. The authors found that approximately $57 \%$ of the investigated municipalities had a population of less than 5,000 inhabitants.

Because there are cities with large populations in Rio de Janeiro interspersed with others with small populations, the identification of scattering trends among the raw incidence rates was not possible in this study. The instability of the indicators in some regions, which was caused by low numbers of cases and small population sizes, led us to use smoothing strategies that took into account the spatial dependency structure and to aggregate the indicators into larger time periods. Studies show that the use of a Bayesian Empirical method improves the estimates for each city and reduces the variability of the indicators. These indexes can consider both the influence of global rates and those of neighboring cities 37,38,39.

Although research findings represent official data, there are some limitations of the Brazilian national information system including slow data processing, underreporting, a high number of deaths with undefined cause and inadequate death certificate filing 40,41 .

Surveillance of AIDS cases is carried through SINAN; however, the Brazilian Ministry of Health has established relationships between SINAN and both SISCEL and SIM to reduce reporting delays and underreporting of AIDS cases. 
The updated number of SINAN cases based on SISCEL and SIM has been available since 2001. From 2001 to 2011, 32\% of cases reported in Rio de Janeiro in individuals aged 60 years or older came from the SISCEL and SIM databases. This highlights a significant improvement in reducing underreporting of AIDS cases.

Although in recent decades we have witnessed major biomedical advances in the diagnosis, treatment and prevention of AIDS, much remains to be done to control the disease.

\section{Resumen}

El objetivo de este estudio fue evaluar las tendencias espaciales y temporales de la epidemia del SIDA en los adultos de edad avanzada en el Estado de Río de Janeiro, Brasil. Se trata de un estudio retrospectivo de técnicas de análisis espacial, utilizando casos de SIDA $(\geq 60$ años) diagnosticados 1997-2011. El modelo de regresión de Poisson se utiliza para acceder a la relación entre año de diagnóstico y la incidencia del SIDA ajustada por sexo. La epidemia del SIDA comenzó en la costa sur del estado y, poco a poco, llegó a las ciudades aledañas. Se encontró que las tasas más altas de la enfermedad en las regiones que rodean Río de Janeiro y Niterói. En 2002-2006, en la ciudad de Niterói, hubo tasas más altas de la enfermedad suavizadas durante el período: 11,87/100.000 (hombres) y 8,5/100.000 (mujeres). Las tasas de SIDA en las personas mayores se han estabilizado en las últimas décadas. Se debe proporcionar una mayor atención al grupo de adultos de edad avanzada, con el fin de prevenir la progresión de la enfermedad en la población.

Síndrome de Inmunodeficiencia Adquirida; VIH;

Anciano; Análisis Espacial
Results of this study indicate that the highest rates of disease in the elderly were found in the region around the large cities of Rio de Janeiro and Niterói. This finding may be related to issues of access to services and knowledge of risks. Risk maps for the geographical distribution of AIDS are needed to guide the direction of HIV-prevention interventions. Preventive health policies aimed at older patients may contribute to reducing the risk of AIDS in the elderly.

\section{Contributors}

N. C. P. Rodrigues was responsible for all aspects regarding the study, ensuring the integrity and accuracy of the paper; contributed to the study design, data analysis, and drafting the paper; approved the final version of the paper. A. S. Almeida, J. U. Braga, G. O’Dwyer, P. C. Apratto Junior, R. P. Daumas, V. T. S. Lino, M. K. N. Andrade, D. L. M. Monteiro and M. B. L. Barros contributed to the data analysis and reviewed and approved the final version of the paper.

\section{Acknowledgments}

To the National School of Public Health (ENSP) of the Oswaldo Cruz Foundation (Fiocruz) and the Faculty of Medical Sciences (FCM) of the State University of Rio de Janeiro (UERJ). 


\section{References}

1. Cardoso SW, Torres TS, Santini-Oliveira M, Marins LM, Veloso VG, Grinsztejn B. Aging with HIV: a practical review. Braz J Infect Dis 2013; 17:464-79.

2. Santos AFM, Assis Md. Vulnerabilidade das idosas ao HIV/AIDS: despertar das políticas públicas e profissionais de saúde no contexto da atenção integral: revisão de literatura. Rev Bras Geriatr Gerontol 2011; 14:147-58.

3. Oliveira ML, Paz LC, Melo GF. Dez anos de epidemia do HIV-AIDS em maiores de 60 anos no Distrito Federal - Brasil. Rev Bras Epidemiol 2013; 16:30-9.

4. Chiao EY, Ries KM, Sande MA. AIDS and the elderly. Clin Infect Dis 1999; 28:740-5.

5. Driemeier M, Andrade SM, Pontes ER, Paniago AM, Cunha RV. Vulnerability to AIDS among the elderly in an urban center in central Brazil. Clinics 2012; 67:19-25.

6. National Institute of Aging. HIV, AIDS, and Older People USA 2009 http://www.nia.nih.gov/health/ publication/hiv-aids-and-older-people (accessed on $12 / \mathrm{Jul} / 2013$ ).

7. Nguyen N, Holodniy M. HIV infection in the elderly. Clin Interv Aging 2008; 3:453-72.

8. Lazarus JV, Nielsen KK. HIV and people over 50 years old in Europe. HIV Med 2010; 11:479-81.

9. Centers for Disease Control and Prevention. Morbidity and Mortality Weekly Report: summary of notifiable diseases. United States, 2010. http:// www.cdc.gov/mmwr/PDF/wk/mm5953.pdf (accessed on $12 / \mathrm{Jul} / 2015$ ).

10. Centers for Disease Control and Prevention. Morbidity and Mortality Weekly Report: summary of notifiable diseases. United States, 2011. http:// www.cdc.gov/mmwr/PDF/wk/mm6053.pdf (accessed on $12 / \mathrm{Jul} / 2015$ ).

11.Carvalho LM, Câmara FP. Epidemiological aspects of acquired immunodeficiency syndrome in older Brazilians: a comparative approach. Braz J Infect Dis 2012; 16:34-7.

12.Jongsthapongpanth A, Bagchi-Sen S. Spatial and sex differences in AIDS mortality in Chiang Rai, Thailand. Health Place 2010; 16:1084-93.

13. Chiu YW, Hsu CE, Wang MQ, Nkhoma ET. Examining geographic and temporal variations of AIDS mortality: evidence of racial disparities. J Natl Med Assoc 2008; 100:788-96.

14. Steinberg S, Fleming P. The geographic distribution of AIDS in the United States: is there a rural epidemic? J Rural Health 2000; 16:11-9.

15. Hogg RS, Schechter MT, Schilder A, Le R, Strathdee SA, Goldstone IL, et al. Access to health care and geographic mobility of HIV/AIDS patients. AIDS Patient Care 1995; 9:297-302.

16. Hogg RS, Whitehead J, Ricketts M, Heath KV, Ng E, Lalonde P, et al. Patterns of geographic mobility of persons with AIDS in Canada from time of AIDS index diagnosis to death. Clin Invest Med 1997; 20:77-83.

17. Wood E, Yip B, Gataric N, Montaner JS, O'Shaughnessy MV, Schechter MT, et al. Determinants of geographic mobility among participants in a population-based HIV/AIDS drug treatment program. Health Place 2000; 6:33-40.
18. Dias PR, Nobre FF. Analise dos padrões de difusõo espacial dos casos de AIDS por estados brasileiros. Cad Saúde Pública 2001; 17:1173-87.

19. Grangeiro A, Escuder MM, Castilho EA. A epidemia de AIDS no Brasil e as desigualdades regionais e de oferta de serviço. Cad Saúde Pública 2010; 26:2355-67.

20. Grangeiro A, Escuder MM, Castilho EA. Magnitude and trend of the AIDS epidemic in Brazilian cities, from 2002 to 2006. Rev Saúde Pública 2010; 44:430-40.

21. Szwarcwald CL, Bastos FI, Barcellos C, Esteves MAP, Castilho EA. Dinâmica da epidemia de AIDS no Município do Rio de Janeiro, no período de 1988-1996: uma aplicação de análise estatística espaço-temporal. Cad Saúde Pública 2001; 17:1123-40

22. Reis CT, Czeresnia D, Barcellos C, Tassinari WS. A interiorização da epidemia de HIV/AIDS e o fluxo intermunicipal de internação hospitalar na Zona da Mata, Minas Gerais, Brasil: uma análise espacial. Cad Saúde Pública 2008; 24:1219-28.

23. Departamento de Vigilância Epidemiológica, Secretaria de Vigilância em Saúde, Ministério da Saúde. Sistema de Informação de Agravos de Notificação. SINAN: normas e rotinas. Brasília: Ministério da Saúde; 2006. (Série A. Normas e Manuais Técnicos).

24. Ministério da Saúde. Manual de procedimento do sistema de informações sobre mortalidade. Brasília: Ministério da Saúde; 2001.

25. Programa Nacional de DST e AIDS Secretaria de Vigilância em Saúde, Ministério da Saúde. Critérios de definição de casos de aids em adultos e crianças. Brasília: Ministério da Saúde; 2003. (Série Manuais, 60).

26. Druck S, Carvalho MS, Monteiro AVM. Análise espacial de áreas. Brasília: Empresa Brasileira de Pesquisa Agropecuária; 2004.

27. Moran PAP. The interpretation of statistical maps. J R Stat Soc Series B Stat Methodol 1948; 10:243-51.

28. Anselin L, Syabri I, Smirnov O. Visualizing Multivariate Spatial Correlation with Dynamically Linked Windows (2002). http://citeseerx.ist.psu. edu/viewdoc/summary?doi=10.1.1.118.7163 (accessed on $12 / \mathrm{Jul} / 2015$ ).

29. Ismail N, Jemain AA. Handling overdispersion with negative binomial and generalized poisson regression models. Casualty actuarial society fórum. http://www.casact.org/pubs/ forum/07wforum/07w109.pdf (accessed on 12/ $\mathrm{Jul} / 2015)$

30. Apratto Junior PC, Lima Barros MB, Daumas RP, Noronha Andrade MK, Monteiro DL, Vincent BR, et al. Trends in AIDS incidence in individuals aged 50 years or older in the city of rio de janeiro, Brazil, 1982-2011: an age-period-cohort analysis. Int J Environ Res Public Health. 2014; 11:7608-21.

31. Rodrigues NC. Age-period cohort analysis of AIDS incidence rates in Rio de Janeiro, Brazil, 19852009. Popul Health Metr 2013; 11:22. 
32. Tomazelli J, Czeresnia D, Barcellos C. Distribuição dos casos de AIDS em mulheres no Rio de Janeiro, de 1982 a 1997: uma análise espacial. Cad Saúde Pública 2003; 19:1049-61.

33. Lopez-De Fede A, Stewart JE, Hardin JW, MayfieldSmith K, Sudduth D. Spatial visualization of multivariate datasets: an analysis of STD and HIV/AIDS diagnosis rates and socioeconomic context using ring maps. Public Health Rep 2011; 126 Suppl 3:115-26.

34. Bastos FI, Barcellos C. Geografia social da AIDS no Brasil. Rev Saúde Pública 1995; 29:52-62.

35. Barcellos C, Bastos FI. Redes sociais e difusão da AIDS no Brasil. Bol Oficina Sanit Panam 1996; 121:11-24.

36. Carrel M, Eron Jr. JJ, Emch M, Hurt CB. Spatial epidemiology of recently acquired HIV infections across rural and urban areas of North Carolina. PLoS One 2014; 9:e88512.

37. Carvalho MS, Cruz OG, Nobre FF. Spatial partitioning using multivariate cluster analysis and a contiguity algorithm. Stat Med 1996; 15:1885-94.
38. Clayton D, Kaldor J. Empirical Bayes estimates of age-standardized relative risks for use in disease mapping. Biometrics 1987; 43:671-81.

39. Marshall RJ. Mapping disease and mortality rates using empirical Bayes estimators. J R Stat Soc Ser C Appl Stat 1991; 40:283-94.

40. Ferreira VMB, Portela MC. Avaliação da subnotificação de casos de Aids no Município do Rio de Janeiro com base em dados do sistema de informações hospitalares do Sistema Único de Saúde. Cad Saúde Pública 1999; 15:317-24.

41. Ministério da Saúde; Organização Pan-Americana da Saúde; Fundação Oswaldo Cruz, organizadores. A experiência brasileira em sistemas de informação em saúde. v. 1. Produção e disseminação de informações sobre saúde no Brasil. Brasília: Editora do Ministério da Saúde; 2009. (Série B. Textos Básicos de Saúde).

Submitted on 11/Oct/2014

Final version resubmitted on 31/Jan/2015

Approved on 02/Mar/2015 